\title{
Prognostic value of the lymph node ratio for lymph-node-positive breast cancer- is it just a denominator problem?
}

\author{
Upali W Jayasinghe ${ }^{1,2^{*}}$, Nirmala Pathmanathan ${ }^{1}$, Elisabeth Elder ${ }^{1}$ and John Boyages ${ }^{3}$
}

\begin{abstract}
Purpose: To examine the prognostic value of lymph node ratio (LNR) for patients with node-positive breast cancer with varying numbers of minimum nodes removed ( $>5,>10$ and $>15$ total node count).

Methods: This study examined the original histopathological reports of 332 node-positive patients treated in the state of New South Wales (NSW), Australia between 1 April 1995 and 30 September 1995. The LNR was defined as the number of positive lymph nodes ( $L N s)$ over the total number of $L N s$ removed. The LNR cutoffs were defined as low-risk, 0.01-0.20; intermediate-risk, 0.21-0.65; and high-risk, LNR >0.65.

Results: The median follow-up was 10.3 years. In multivariate analysis, LNR was an independent predictor of 10-year breast cancer specific survival when $>5$ nodes were removed. However, LNR was not an independent predictor when > 15 nodes were removed. In a multivariate analysis the relative risk of death (RR) decreased from 2.20 to 1.05 for intermediate-risk LNR and from 3.07 to 2.64 for high-risk while P values increased from 0.027 to 0.957 for intermediate-risk LNR and 0.018 to 0.322 for high-risk with the number of nodes removed increasing from $>5$ to $>15$.

Conclusions: Although LNR is important for patients with low node denominators, for patients with macroscopic nodal metastases in several nodes following an axillary dissection who have more than 15 nodes dissected, the oncologist can be satisfied that prognosis, selection of adjuvant chemotherapy and radiotherapy fields can be based on the numerator of the positive nodes.
\end{abstract}

Keywords: Lymph node ratio; pN stage; Number of nodes removed; Breast cancer specific survival

\section{Introduction}

Axillary lymph node status is one of the most important prognostic factors for breast cancer (Schiffman et al. 2011; Vinh-Hung et al. 2003; Yiangou et al. 1999). Practice has changed from full dissection and/or radiation of the axilla (Fisher et al. 1985) to the use of sentinel node biopsy (SNB) for many patients (Krag et al. 1998). More recently the Z00011 trial (Giuliano et al. 2010; Giuliano et al. 2011; Caudle et al. 2011) was conducted to determine the effects of completion axillary lymph node dissection (ALND) on overall survival in patients with sentinel lymph node (SLN) metastases treated with breast conservation and adjuvant therapy including radiotherapy.

\footnotetext{
* Correspondence: upali.jay@unsw.edu.au

${ }^{1}$ Westmead Breast Cancer Institute, Westmead, New South Wales, Australia ${ }^{2}$ Faculty of Medicine, University of New South Wales, Sydney, New South Wales, Australia

Full list of author information is available at the end of the article
}

In an era when ALND is performed selectively in patients with a high risk of nodal involvement, the accuracy of the surgical procedure assumes greater importance. There is still debate about what constitutes an adequate axillary dissection in terms of the total number of lymph nodes removed. The current American Joint Committee on Cancer (AJCC) Staging System uses the number of positive LNs and classifies a patient with 1 to 3 positive nodes as having $\mathrm{pN} 1$ disease, 4 to 9 positive nodes as pN2 disease, and 10 or more nodes as pN3 (Singletary et al. 2003; Rabban 2010). However, the number of involved lymph nodes is also dependant on the total number of lymph nodes removed and examined, which in turn depends on surgical and pathologic procedures (Vinh-Hung et al. 2009; Wang et al. 2012). Although some studies noted that six nodes were the minimum number of nodes needed to adequately assess 
the axilla (Katz et al. 2008), it is generally accepted that greater than 10 LNs are required (National Comprehensive Cancer Network 2013). One study found that at least five and 10 nodes are required for node-negative and node-positive patients respectively (Fisher et al. 1981).

Several studies have examined the notion of the LN ratio (LNR), defined as the number of positive LNs over the number of LNs removed, as a potential prognostic factor in breast cancer (Voordeckers et al. 2004; VinhHung et al. 2010; van der Wal et al. 2002; Truong et al. 2010; Danko et al. 2010). Some studies have demonstrated that the LNR was useful in estimating prognosis and should be considered in conjunction with the absolute number of positive lymph nodes in helping guide decisions for breast cancer management (Chagpar et al. 2006; Chagpar et al. 2007).

The extent of axillary dissection varies from centre to centre and country to country and of course, surgeon to surgeon and this has an impact on the risk of locoregional recurrence and survival and even account for variations in the benefit of post-mastectomy radiation (Boyages \& Langlands 1998). An increasing dilemma for clinicians is whether to give patients with $1-3 \mathrm{~N}+$ postmastectomy radiation therapy, particularly if a patient has had an adequate axillary dissection. In other words, could the survival and loco-regional control benefit of radiation be simply due to under-staging and, does the recent Oxford meta-analysis really mean that every patient with 1-3 nodes positive require post-mastectomy radiation (Zhou et al. 2013). Further, there is ongoing debate, not only about the use of radiation, but also the areas to be treated particularly with respect to the internal mammary chain (Vrana et al. 2013).

When $\leq 10$ nodes are removed, there is a greater probability that some patients with $\geq 4$ positive nodes will be misclassified as having one to three positive nodes (Fisher et al. 1981). In other words patients are potentially understaged. The median number of nodes dissected was 11 and 7, for Canadian (Ragaz et al. 1997) and Danish (Overgaard et al. 1997) studies respectively which first reported the potential benefit from postmastectomy radiation. A previous study at our institution examined an average of 25 nodes per case (range, 8-54), and using strict anatomical criteria, the mean number of LN found in axillary level I, II and III were 8 (range, 2-43), 4 (range, 0-19) and 3 (range, 0-11) respectively (Chua et al. 2002).

Several studies have identified that LNR, categorized as low risk $(\mathrm{LNR}=0.01-0.20)$, intermediate risk $(\mathrm{LNR}=$ $0.21-0.65)$ and high risk (LNR >0.65), was better at predicting breast cancer specific mortality than $\mathrm{pN}$ staging as a way to account for the variability in the nodal count (the denominator), for various levels of dissection and number of positive lymph nodes (the numerator) (VinhHung et al. 2009; Vinh-Hung et al. 2010; van der Wal et al. 2002; Danko et al. 2010; Chagpar et al. 2011). In the current TNM classification system, nodal status is based on the absolute number of involved lymph nodes and does not take into account the total number of lymph nodes removed and assumes that all lymph node dissections are the same. Although TNM classification remains the basis of breast cancer staging, LNR may add important prognostic information. Such a ratio, which contains both information regarding the number of positive nodes as well as the denominator as a defacto measure of the adequacy of the dissection, may be superior to the current AJCC staging system in terms of predicting outcomes (Chagpar et al. 2011).

Few studies have examined LNR in patients with varying total numbers of lymph nodes removed. The aim of this study was to examine whether the prognostic value of LNR depends on the number of nodes removed $(>5,>$ 10 and $>15$ ) using data from a statewide population study involving 154 surgeons and 58 pathology practices in Australia's largest state.

\section{Method}

\section{Patient selection}

The population studied included 848 consecutive patients with invasive breast cancer who had original histological reports and treated in New South Wales (NSW), Australia between 1 April 1995 and 30 September 1995. This was a population-based study collecting data from multiple treatment centers via a notification process involving a central cancer registry. Only patients who had treatment to their breast combined with axillary clearance surgery were included $(n=848)$.

A total of 154 surgeons performed surgery on 848 patients using 58 different pathology practices. There were 332 nodes positive patients, 515 node-negative and an unknown number of nodes examined $(n=1)$, (total including nodes negative is 848) during the six months period. Patterns of care to the breast in this cohort have been previously published (Boyages et al. 2010). Patients with $<6$ nodes identified $(n=7)$ or node-negative breast cancer $(n=515)$ were excluded from the analysis.

The study, therefore included, three hundred and twenty five lymph node-positive cases with $>5$ nodes dissected, 262 with $>10$ nodes and 149 with $>15$ nodes in the analysis. All node-positive patients who had surgery to their breast and axillary clearance surgery with $>5$ nodes removed ( $34 \%$ had conservative treatment and $66 \%$ mastectomy) were included. One hundred and thirty six had radiation therapy ( $85 \%$ of breast conservation patients and 20\% of mastectomy patients) and 181 had chemotherapy. The median number of axillary lymph 
nodes removed was 15 (range, 6-43). Sentinel node biopsy technique was not used at that time.

\section{Data analysis}

The New South Wales (NSW) Central Cancer Registry (CCR) maintains a register of all cases of cancer diagnosed in NSW since the beginning of 1972. All cases of breast cancer not known to be dead by the NSW CCR were matched against the death records from the NSW Registry of Births, Deaths and Marriages, enhanced by information obtained from the Australian Bureau of Statistics. Ten-year breast cancer survival data of the study group were provided by the NSW CCR. Follow-up time was calculated from the date of first treatment (surgery) to the date of last follow-up or death. The median follow-up was 10.3 years (interquartile range, $5.2-10.5$ years).

The LNR was calculated as the total number of positive lymph nodes divided by the total number of lymph nodes found and examined (the denominator). The cohort was then divided into 3 groups based on established LNR cutoffs (Vinh-Hung et al. 2009; Vinh-Hung et al. 2010; van der Wal et al. 2002; Danko et al. 2010; Chagpar et al. 2011). Accordingly, in this study, the LNR cutoffs were defined as low-risk, 0.01-0.20; intermediaterisk, 0.21-0.65; and high-risk, >0.65. We examined the prognostic value of lymph node ratio (LNR) for patients with node-positive breast cancer with varying numbers of minimum nodes removed $(>5,>10$ and $>15$ total node count). We also examined the impact of minimum number of lymph nodes removed (all patients, $\leq 10$ or $>10$ and $\leq 15$ or $>15$ ) to compare the performance of LNR as prognostic indicators.

Comparison of categories within a characteristic was carried out with the Pearson Chi-square test and, if any of the expected frequencies was less than five, the Fisher exact test was used. A preliminary univariate survival analysis was performed with the Kaplan-Meier method or Cox proportional hazard regression and groups were compared with the log-rank test. Significant or marginally significant predictors in the univariate analysis were included in the multivariate analysis. The independent prognostic effect of LNR was investigated using Cox proportional hazard regression, adjusting for $\mathrm{pN}$ stage, age $(<40, \geq 40)$, pathological tumour size ( $\leq 20 \mathrm{~mm}$, or $>20 \mathrm{~mm}$ ), histological grade $(1,2$ or 3$)$, ER status (negative or positive) and chemotherapy (no or yes). Radiation therapy (no or yes) and hormone therapy (no or yes) were not significant in univariate analysis. All statistical analyses were performed using SPSS statistical software (IBM SPSS Statistics version 19, New York, USA). Survival plots were generated using SAS statistical software (version 9.3; SAS Institute, Cary, NC). Our study was approved by the NSW Population and Health Services Research Ethics Committee.

\section{Results}

The mean age of patients at diagnosis was 56 years (range, 25-91 years). The clinical and pathological characteristics of patients and treatment of patients are shown in Table 1. Compared to patients with low-risk LNR, patients with intermediate- or high-risk LNR were more likely to have pathological tumour size over $20 \mathrm{~mm}$ (41\% vs 67\%, P<0.001), more likely to be grade 3 (54\% high-risk vs $36 \%$ low-risk, $\mathrm{P}=0.02)$, have pN2 (4-9 N+) disease (28.2\% high-risk vs $2.7 \%$ lowrisk, $\mathrm{P}<0.001)$ or $\mathrm{pN} 3(\geq 10 \mathrm{~N}+) \quad 71.8 \%$ high-risk vs $13.1 \%$ intermediate-risk, $\mathrm{P}<0.001)$, radiation therapy ( $33 \%$ vs $54 \%, \mathrm{P}=0.001$ ) and chemotherapy (50\% vs $>60 \%$, $\mathrm{P}=0.007$ ) (Table 1). The relationship with other patient or tumour characteristics did not vary by LNR groups. In particular, LNR was not different by age at diagnosis. Similarly, distribution of ER and hormone therapy over the LNR groups was similar (Table 1).

At a median follow-up of 10.3 years, 37 of 187 patients (19.8\%) with low-risk LNR have died of breast cancer compared to 46 of 99 (46.5\%) with intermediate-risk and 23 of 39 (59.0\%) with high-risk LNR $(\mathrm{P}<0.001)$. Table 2 shows two scenarios using a denominator of 10 or 15 nodes identified in the final pathology report. Although for patients with 1-3 nodes positive, increasing LNR was associated with increasing mortality when $\leq 10$ (lowrisk: $16.7 \%$; intermediate risk: $41.2 \%)$ or $>10$ nodes were removed (low-risk: 19.7\%; intermediate risk: 45.5\%), LNR lost its significance (low risk: $15.9 \%$ and no other risk categories) when more than 15 nodes were dissected. Figure 1a shows, that for patients with pN1 (1-3 N+) disease, patients with more than 15 nodes dissected had a 10 -year breast cancer-specific survival of $84 \%$ compared to $71 \%$ when up to 15 nodes were dissected ( $\mathrm{p}=0.035$ ). Figure $1 \mathrm{~b}$ shows the corresponding 10-year breast cancer specific survival rates for all possible combinations of LNR for patients with pN1 (1-3 N+). The best 10-year breast cancer specific survival rate was $84 \%$ for a low LNR and high nodal denominator ( $>15$ nodes identified). In contrast, for $\mathrm{pN} 1$ patients with up to 15 nodes dissected and a low LNR the 10-year survival rate was $76 \%$ but dropped to $55 \%$ for an intermediate LNR ( $\mathrm{p}=0.024)$. There were no patients with a high LNR in the pN1 subgroup.

For patients with 10 or more positive nodes (pN3) mortality was over $60 \%$ irrespective of LNR in a clinical setting where most oncologists would advise postmastectomy RT. For pN2 disease (4-9 nodes positive), LNR only made a difference in the setting where $\leq 10$ nodes were dissected again implying that if the denominator increased to 15 or more, more patients would 
Table 1 Clinicopathologic characteristics of 325 women with lymph node-positive breast cancer according to lymph node ratio (LNR)

\begin{tabular}{|c|c|c|c|c|c|c|c|c|c|}
\hline \multirow[t]{5}{*}{ Characteristic } & \multirow[b]{5}{*}{$P$ value } & \multicolumn{8}{|c|}{ Lymph node ratio } \\
\hline & & \multirow{3}{*}{\multicolumn{2}{|c|}{$\begin{array}{l}\text { Low-risk } \\
(\leq 0.20) \\
(n=187)\end{array}$}} & \multirow{3}{*}{\multicolumn{2}{|c|}{$\begin{array}{l}\text { Intermediate-risk } \\
(>0.20 \& \leq 0.65) \\
(n=99)\end{array}$}} & \multirow{3}{*}{\multicolumn{2}{|c|}{$\begin{array}{l}\text { High-risk } \\
(>0.65) \\
(\mathrm{n}=39)\end{array}$}} & \multirow{3}{*}{\multicolumn{2}{|c|}{$\begin{array}{l}\text { All } \\
(n=325)\end{array}$}} \\
\hline & & & & & & & & & \\
\hline & & & & & & & & & \\
\hline & & No. & $(\%)$ & No. & $(\%)$ & No. & $(\%)$ & No. & (\%) \\
\hline Age, yrs & 0.622 & & & & & & & & \\
\hline$<40$ & & 22 & 11.8 & 8 & 8.1 & 3 & 7.7 & 33 & 10.2 \\
\hline$\geq 40$ & & 165 & 88.2 & 91 & 91.9 & 36 & 92.3 & 292 & 89.8 \\
\hline Tumour size, mm & $<0.001$ & & & & & & & & \\
\hline $0-20$ & & 110 & 58.8 & 33 & 33.3 & 13 & 33.3 & 156 & 48.0 \\
\hline$>20$ & & 77 & 41.2 & 66 & 66.7 & 26 & 66.7 & 169 & 52.0 \\
\hline Histological grade & 0.063 & & & & & & & & \\
\hline 1 & $(0.047)$ & 30 & 16.0 & 8 & 8.1 & 4 & 10.3 & 42 & 12.9 \\
\hline 2 & & 74 & 39.6 & 40 & 40.4 & 8 & 20.5 & 122 & 37.5 \\
\hline 3 & & 68 & 36.4 & 43 & 43.4 & 21 & 53.8 & 132 & 40.6 \\
\hline Unknown & & 15 & 8.0 & 8 & 8.1 & 6 & 15.4 & 29 & 8.9 \\
\hline ER status & 0.362 & & & & & & & & \\
\hline Negative & $(0.869)$ & 15 & 8.0 & 7 & 7.1 & 2 & 5.1 & 24 & 7.4 \\
\hline Positive & & 48 & 25.7 & 16 & 16.2 & 7 & 17.9 & 71 & 21.8 \\
\hline Unknown & & 124 & 66.3 & 76 & 76.8 & 30 & 76.9 & 230 & 70.8 \\
\hline No. of nodes removed & 0.249 & & & & & & & & \\
\hline $6-10$ & & 30 & 16.0 & 26 & 26.3 & 7 & 17.9 & 63 & 19.4 \\
\hline $11-15$ & & 64 & 34.2 & 35 & 35.4 & 14 & 35.9 & 113 & 34.8 \\
\hline$>15$ & & 93 & 49.7 & 38 & 38.4 & 18 & 46.2 & 149 & 45.8 \\
\hline pN stage & $<0.001$ & & & & & & & & \\
\hline $\mathrm{pN} 1(1-3)$ & & 182 & 97.3 & 28 & 28.3 & 0 & 0.0 & 210 & 64.6 \\
\hline pN2 (4-9) & & 5 & 2.7 & 58 & 58.6 & 11 & 28.2 & 74 & 22.8 \\
\hline pN3 $(\geq 10)$ & & 0 & 0.0 & 13 & 13.1 & 28 & 71.8 & 41 & 12.6 \\
\hline Radiation therapy & 0.001 & & & & & & & & \\
\hline No & & 125 & 66.8 & 45 & 45.9 & 18 & 46.2 & 188 & 58.0 \\
\hline Yes & & 62 & 33.2 & 53 & 54.1 & 21 & 53.8 & 136 & 42.0 \\
\hline Chemotherapy & 0.007 & & & & & & & & \\
\hline No & & 92 & 50.3 & 30 & 30.9 & 15 & 39.5 & 137 & 43.1 \\
\hline Yes & & 91 & 49.7 & 67 & 69.1 & 23 & 60.5 & 181 & 56.9 \\
\hline Hormone therapy & 0.278 & & & & & & & & \\
\hline No & & 79 & 42.2 & 33 & 33.3 & 13 & 33.3 & 125 & 38.5 \\
\hline Yes & & 108 & 57.8 & 66 & 66.7 & 26 & 66.7 & 200 & 61.5 \\
\hline
\end{tabular}

$\mathrm{P}$ values are for comparison of categories of each variable by lymph node ratio using the Pearson chi-square test or the Fisher exact test. For characteristics with an unknown category the $\mathrm{P}$ values without unknown category are shown within parentheses. Patients with $>5$ nodes removed included in the table.

Missing values: Radiation therapy $=1$, Chemotherapy $=7$.

have had disease that would have been pN3 $(\geq 10 \mathrm{~N}+)$ (Table 2).

We also analyzed LNR by number of nodes dissected (all patients or $\leq 15$ or $>15$ ) (Table 3). Although increasing LNR was a predictor of breast cancer mortality for all patients by univariate or multivariate analysis, it once again lost its significance when more than 15 nodes were identified (Table 3). In a multivariate analysis the relative risk of death (RR) decreased from 2.20 to 1.05 for intermediate-risk LNR and from 3.07 to 2.64 for highrisk while $\mathrm{P}$ values increased from 0.027 to 0.957 for intermediate-risk LNR and 0.018 to 0.322 for high-risk 
Table 2 Percentage of breast cancer deaths by LNR and pN stage for varying total numbers of nodes removed

\begin{tabular}{|c|c|c|c|c|c|}
\hline \multirow[t]{3}{*}{ pN stage } & \multirow[t]{3}{*}{ Nodes removed } & \multicolumn{4}{|c|}{ Number of deaths/total (\%) for LNR } \\
\hline & & Low-risk & Intermediate-risk & High-risk & All \\
\hline & & $(\leq 0.20)$ & $(>0.20 \& \leq 0.65)$ & $(>0.65)$ & \\
\hline \multicolumn{6}{|c|}{ Nodes removed $\leq 10$ and $>10$} \\
\hline \multirow[t]{2}{*}{ pN1 (1-3) } & $\leq 10$ & $5 / 30(16.7)$ & $7 / 17(41.2)$ & * & $12 / 47(25.5)$ \\
\hline & $>10$ & $30 / 152(19.7)$ & $5 / 11(45.5)$ & * & $35 / 163(21.5)$ \\
\hline \multirow[t]{2}{*}{ pN2 (4-9) } & $\leq 10$ & * & $2 / 9(22.2)$ & $3 / 7(42.9)$ & $5 / 16(31.3)$ \\
\hline & $>10$ & $2 / 5(40.0)$ & $24 / 49(49.0)$ & $2 / 4(50.0)$ & $28 / 58(48.3)$ \\
\hline \multirow[t]{2}{*}{ pN3 $(\geq 10)$} & $\leq 10$ & * & * & * & * \\
\hline & $>10$ & * & $8 / 13(61.5)$ & $18 / 28(64.3)$ & $26 / 41(63.4)$ \\
\hline \multicolumn{6}{|c|}{ Nodes removed $\leq 15$ and $>15$} \\
\hline \multirow[t]{2}{*}{ pN1 (1-3) } & $\leq 15$ & 21/94 (22.3) & $12 / 28(42.9)$ & * & $33 / 122(27.0)$ \\
\hline & $>15$ & 14/88 (15.9) & * & * & 14/88 (15.9) \\
\hline \multirow[t]{2}{*}{ pN2 (4-9) } & $\leq 15$ & * & 15/33 (45.5) & $5 / 11(45.5)$ & $20 / 44(45.5)$ \\
\hline & $>15$ & $2 / 5(40.0)$ & $11 / 25(44.0)$ & * & $13 / 30(43.3)$ \\
\hline \multirow[t]{2}{*}{ pN3 $(\geq 10)$} & $\leq 15$ & * & * & $5 / 10(50.0)$ & $5 / 10(50.0)$ \\
\hline & $>15$ & * & $8 / 13(61.5)$ & 13/18 (72.2) & $21 / 31(67.7)$ \\
\hline
\end{tabular}

*no cases from this category.

with the number of nodes removed increasing from $>5$ to $>15$.

\section{Discussion}

LNR has been widely demonstrated to be a useful alternative to predict survival in many cancers including lung cancer (Matsuguma et al. 2012; Jonnalagadda et al. 2011), colon cancer (Greenberg et al. 2011; Berger et al. 2005), pancreas (Berger et al. 2004), bladder (Herr 2003), gastric cancer (Tong et al. 2011; Hong et al. 2011) and particular breast cancer (Schiffman et al. 2011; Vinh-Hung et al. 2009; Danko et al. 2010; Chagpar et al. 2011). In contrast to many other studies, we found that LNR was not important if an adequate axillary dissection was performed. We hypothesise that LNR is a problem of the denominator.
When patients with breast cancer have a nodal dissection identifying more than 15 nodes, LNR loses its significance.

Woodward et al. (2006) conducted a systematic review based on 24 studies published from 1994 to 2005 totaling 32,299 patients supporting the greater prognostic value of LNR compared to number of involved nodes. Table 4 shows the prognostic value of LNR for more recent studies published since 2008 and these studies again confirmed the superiority of LNR (Schiffman et al. 2011; Vinh-Hung et al. 2009; Danko et al. 2010; Chagpar et al. 2011; Saxena et al. 2012; Truong et al. 2008; Li et al. 2012; Duraker et al. 2013; Dings et al. 2013). However, in these studies all patients were included in the analysis and the denominator of LNR (number of nodes removed) starting from one node found leading to high

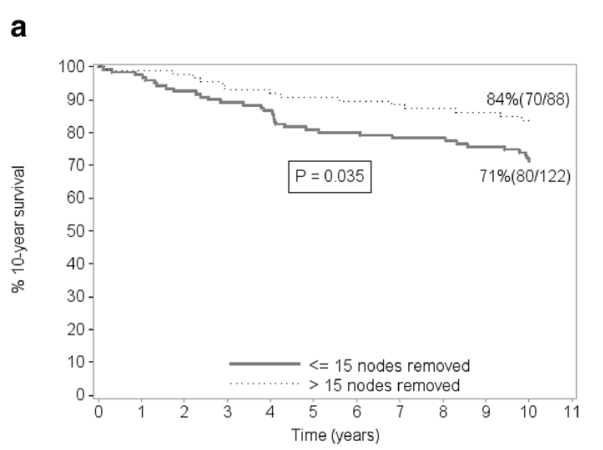

b

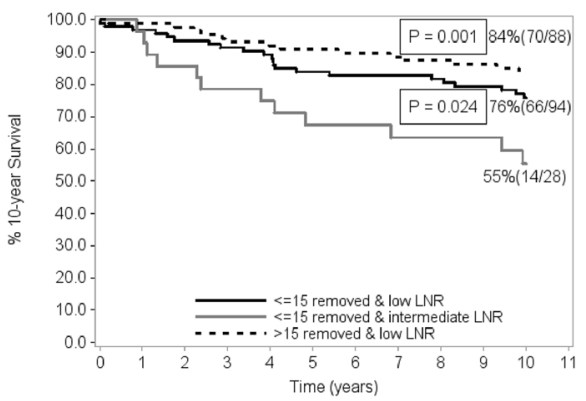

Figure 1 Kaplan-Meier breast cancer specific survival estimates according to the number of nodes removed. (a) shows overall survival for pN1 (1-3) stage. Numbers in parentheses indicate total number and number at risk. (b) shows overall survival for pN1 (1-3) stage by LNR. Numbers in parentheses indicate total number and number at risk. There were no cases from high risk LNR for $\leq 15$ nodes removed. All cases for pN1 stage were low-risk LNR for $>15$ nodes removed. P values are from the log rank-test with intermediate LNR as the reference. 
Table 3 Results of univariate and multivariate survival analysis at 10 -year follow up

\begin{tabular}{|c|c|c|c|c|c|c|c|c|c|c|}
\hline \multirow[b]{3}{*}{ Factor } & \multicolumn{4}{|c|}{ All patients $(n=318)$} & \multirow{2}{*}{\multicolumn{3}{|c|}{$\begin{array}{l}\text { lymph nodes removed } \leq 15 \\
(\mathrm{n}=172) \\
\text { Multivariate analysis cox } \\
\text { regression analysis }\end{array}$}} & \multirow{2}{*}{\multicolumn{3}{|c|}{$\begin{array}{l}\text { lymph nodes removed }>15 \\
(\mathrm{n}=146) \\
\text { Multivariate analysis cox } \\
\text { regression analysis }\end{array}$}} \\
\hline & \multicolumn{2}{|c|}{$\begin{array}{l}\text { Univariate cox } \\
\text { regression analysis }\end{array}$} & \multicolumn{2}{|c|}{$\begin{array}{l}\text { Multivariate cox } \\
\text { regression analysis }\end{array}$} & & & & & & \\
\hline & RR $(95 \%$ Cl) & $\mathbf{P}$ & $\mathrm{RR}(95 \% \mathrm{Cl})$ & $\mathbf{P}$ & No. & RR $(95 \% \mathrm{Cl})$ & $\mathbf{P}$ & No. & RR (95\% Cl) & $\mathbf{P}$ \\
\hline \multicolumn{11}{|l|}{ LNR } \\
\hline$\leq 0.20$ & 1.00 & & 1.00 & & 92 & 1.00 & & 93 & 1 & \\
\hline$>0.2-0.65$ & $2.91(1.90-4.47)$ & $<.001$ & $2.20(1.09-4.41)$ & 0.027 & 59 & $1.94(0.91-4.12)$ & 0.085 & 38 & $1.05(0.20-5.54)$ & 0.957 \\
\hline$>0.65$ & $4.31(2.56-7.25)$ & $<.001$ & $3.07(1.21-7.80)$ & 0.018 & 21 & $2.03(0.56-7.33)$ & 0.282 & 18 & $2.64(0.39-18.04)$ & 0.322 \\
\hline \multicolumn{11}{|l|}{ pN stage } \\
\hline pN1 (1-3) & 1.00 & & 1.00 & & 118 & 1.00 & & 88 & 1 & \\
\hline pN2 (4-9) & $2.52(1.62-3.91)$ & $<.001$ & $1.28(0.63-2.60)$ & 0.500 & 44 & $1.15(0.51-2.60)$ & 0.745 & 30 & $4.31(0.88-21.20)$ & 0.073 \\
\hline pN3 $(\geq 10)$ & $3.85(2.38-6.21)$ & $<.001$ & $1.31(0.56-3.08)$ & 0.533 & 10 & $1.03(0.23-4.64)$ & 0.970 & 31 & $5.03(0.86-29.45)$ & 0.073 \\
\hline \multicolumn{11}{|c|}{ Age at diagnosis } \\
\hline$<40$ & $1.68(0.99-2.86)$ & 0.056 & $1.82(1.03-3.22)$ & 0.038 & 15 & $1.49(0.61-3.66)$ & 0.384 & 18 & $3.43(1.53-7.69)$ & 0.003 \\
\hline$\geq 40$ & 1.00 & & 1.00 & & 157 & 1.00 & & 131 & 1.00 & \\
\hline \multicolumn{11}{|c|}{ Tumour size, mm } \\
\hline $1-20$ & 1.00 & & 1.00 & & 83 & 1.00 & & 72 & 1.00 & \\
\hline$>20$ & $2.25(1.51-3.37)$ & $<.001$ & $1.52(0.99-2.35)$ & 0.058 & 89 & $1.95(1.08-3.51)$ & 0.027 & 77 & $0.76(0.35-1.64)$ & 0.487 \\
\hline \multicolumn{11}{|c|}{ Histological grade } \\
\hline 1 & 1.00 & & 1.00 & & 22 & 1.00 & & 20 & 1.00 & \\
\hline 2 & $2.16(0.97-4.83)$ & 0.060 & $1.84(0.81-4.18)$ & 0.143 & 58 & $2.18(0.63-7.60)$ & 0.221 & 62 & $1.79(0.57-5.60)$ & 0.318 \\
\hline 3 & $3.21(1.46-7.05)$ & 0.004 & $2.21(0.98-4.95)$ & 0.055 & 77 & $3.73(1.13-12.32)$ & 0.031 & 53 & $1.40(0.42-4.60)$ & 0.584 \\
\hline Unknown & $1.35(0.45-4.02)$ & 0.590 & $1.03(0.34-3.11)$ & 0.958 & 15 & $1.51(0.30-7.60)$ & 0.619 & 14 & $0.73(0.15-3.69)$ & 0.706 \\
\hline \multicolumn{11}{|l|}{ ER } \\
\hline Negative & 1.00 & & 1.00 & & 11 & 1.00 & & 13 & 1.00 & \\
\hline Positive & $0.37(0.18-0.77)$ & 0.008 & $0.49(0.23-1.06)$ & 0.071 & 36 & $0.59(0.19-1.87)$ & 0.367 & 35 & $0.20(0.06-0.65)$ & 0.007 \\
\hline Unknown & $0.59(0.32-1.09)$ & 0.091 & $0.60(0.32-1.13)$ & 0.115 & 125 & $0.76(0.29-1.95)$ & 0.562 & 101 & $0.26(0.10-0.66)$ & 0.005 \\
\hline \multicolumn{11}{|c|}{ Chemotherapy } \\
\hline No & 1.00 & & 1.00 & & 96 & 1.00 & & 61 & 1.00 & \\
\hline Yes & $1.58(1.05-2.37)$ & 0.028 & $1.04(0.67-1.61)$ & 0.860 & 76 & $1.24(0.69-2.22)$ & 0.480 & 85 & $0.61(0.29-1.30)$ & 0.202 \\
\hline
\end{tabular}

RR: Relative risk of dying; $95 \% \mathrm{Cl}$ : $95 \%$ confidence interval of relative risk.

$P$ value is for comparison of each category with the reference category.

Number in each category is shown in Table 1. Seven missing values for chemotherapy.

Radiation therapy $(P=0.587)$ and hormone therapy $(P=0.762)$ are not significant in univariate analysis and not included in multivariate analysis.

LNR's when the denominator was low and reduced survival simply because of under-staging of the axilla. Similar to our study all of these studies but one examined the prognostic value of LNR after adjustment for $\mathrm{pN}$ stage. We found that LNR was no longer significant when the denominator was $>10$ (Tables 2 and 3) and particularly when $>15$ nodes were identified (Table 3).

The likelihood of finding positive nodes in the axilla increases with the number of nodes removed, similarly the likelihood of having residual disease in the axilla decreases with more extensive dissection (Krag \& Single 2003; McMasters 2003). In this study, LNR appeared to be important only for patients who had $<10$ nodes identified by the pathologist after an axillary dissection. Once the level of dissection of the axilla increased to 10 or more nodes and particularly more than 15 nodes, LNR was not significant in a multivariate analysis.

The study demonstrates that the LNR predicted survival more accurately than $\mathrm{pN}$ stage for all patients and when both $\leq 15$ or $>15$ nodes removed were included in the analysis (Table 3) consistent with other studies in which all patients with varying node counts were included in the analysis (Vinh-Hung et al. 2009; Voordeckers et al. 2004; Truong et al. 2005; Ahn et al. 2011). In our series, almost half of our patients (45.9\%) had a denominator of $>15$ nodes removed. In a large study from the Netherlands, $37.4 \%$ of patients had $>15$ nodes removed (Dings et al. 2013). In a multivariate analysis relative 
Table 4 Recent studies (2008-2013) of ratios of involved nodes in breast cancer

\begin{tabular}{|c|c|c|c|c|c|c|c|c|}
\hline Study & Years & $\begin{array}{l}\text { No. of } \\
\text { patients }\end{array}$ & $\begin{array}{l}\text { Selection of } \\
\text { patients* }\end{array}$ & $\begin{array}{l}\text { LNR cut-off } \\
\text { or groups }\end{array}$ & $\begin{array}{l}\text { Follow-up } \\
\text { period }\end{array}$ & $\begin{array}{l}\text { Outcome and Prognostic role } \\
\text { of LNR in multivariate analysis }\end{array}$ & $\begin{array}{l}\text { Nodes removed } \\
\text { median (range) }\end{array}$ & $\begin{array}{l}\text { Population/Institution } \\
\text { study }\end{array}$ \\
\hline \multirow[t]{2}{*}{ Truong et al. 2008} & \multirow[t]{2}{*}{ 1988-1997 } & \multirow[t]{2}{*}{4571} & $\mathrm{~T}_{1}-\mathrm{T}_{2}$ & $\leq 0.25$ & \multirow[t]{2}{*}{14 years } & \multirow[t]{2}{*}{ BCCS and OS significant } & \multirow[t]{2}{*}{$15(1-50)$} & \multirow[t]{2}{*}{ Population } \\
\hline & & & Node-positive & $>0.25$ & & & & \\
\hline \multirow[t]{2}{*}{ Vinh-Hung et al. 2009} & \multirow[t]{2}{*}{ 1980-2004 } & \multirow[t]{2}{*}{1829} & $\mathrm{~T}_{1}-\mathrm{T}_{3}$ & 1. LNR, continuous. & \multirow[t]{2}{*}{10 years } & \multirow{2}{*}{$\begin{array}{l}\text { BCSS significant for continuous and } \\
\text { categorical LNR }\end{array}$} & \multirow[t]{2}{*}{$14(1-X)$} & \multirow[t]{2}{*}{ Population } \\
\hline & & & Node-positive & 2. $\leq 0.20,0.21-0.65,>0.65$ & & & & \\
\hline \multirow[t]{2}{*}{ Danko et al. 2010} & \multirow[t]{2}{*}{$1985-2005$} & \multirow[t]{2}{*}{1788} & $\mathrm{~T}_{1}-\mathrm{T}_{3}$ & $\leq 0.20,0.21-0.65,>0.65$ & \multirow[t]{2}{*}{10 years } & \multirow[t]{2}{*}{ DFS and OS significant } & \multirow[t]{2}{*}{$17(1-57)$} & \multirow[t]{2}{*}{ Institution } \\
\hline & & & Node-positive & & & & & \\
\hline \multirow[t]{2}{*}{ Schiffman et al. 2011} & \multirow[t]{2}{*}{ 1996-2007 } & \multirow[t]{2}{*}{556} & $\mathrm{~T}_{1}-\mathrm{T}_{3}$ & $\leq 0.20,0.21-0.65,>0.65$ & \multirow[t]{2}{*}{5 years } & \multirow[t]{2}{*}{ DFS and OS significant } & \multirow[t]{2}{*}{$3(1-52)$} & \multirow[t]{2}{*}{ Population } \\
\hline & & & Node-positive & & & & & \\
\hline \multirow[t]{2}{*}{ Chagpar et al. 2011} & \multirow[t]{2}{*}{ 1956-1982 } & \multirow[t]{2}{*}{319} & $\mathrm{~T}_{1}-\mathrm{T}_{3}$ & $\leq 0.20,0.21-0.65,>0.65$ & \multirow[t]{2}{*}{40 years } & \multirow[t]{2}{*}{ OS significant } & \multirow[t]{2}{*}{$13(1-48)$} & Institution \\
\hline & & & Node-positive & & & & & \\
\hline Li et al. 2012 & 1998-2000 & 127 & $\mathrm{~T} 1-\mathrm{T} 4$ & LNR, continuous. & 10.9 years & OS significant & $x$ & Institution \\
\hline & & & Node-positive & & & & & \\
\hline Saxena et al. 2012 & 1990-2007 & 1589 & $\mathrm{~T} 1-\mathrm{T} 3$ & $\leq .20,0.21-0.65,>0.65$ & 5 years & OS significant & $15(1-X)$ & Institution \\
\hline & & & Node-positive & & & & & \\
\hline Duraker et al. 2013 & 1993-2002 & 2151 & T1-T3 & $\leq .20,0.21-0.65,>0.65$ & 7 years & DFS significant & $14(1-46)$ & Institution \\
\hline & & & Node-positive & & & & & \\
\hline Dings et al. 2013 & 1999-2005 & 25315 & $\mathrm{~T} 1-\mathrm{T} 3$ & $\leq .20,0.21-0.65,>0.65$ & 10 years & OS significant & $14(1-90)$ & Population \\
\hline & & & Node-positive & & & & & \\
\hline Current series & 1995 & 325 & $\mathrm{~T}_{1}-\mathrm{T}_{3}$ & $\leq 0.20,0.21-0.65,>0.65$ & 10 years & $\begin{array}{l}\text { 1. BCSS not significant if }>15 \text { nodes } \\
\text { removed. }\end{array}$ & $15(6-43)$ & Population \\
\hline & & & Node-positive & & & 2. BCSS significant for all patients. & & \\
\hline
\end{tabular}

Notes: *Node-positive patients were considered if possible.

BCSS-breast cancer specific survival. DFS-disease-free survival.

OS-overall survival from any cause or cause not mentioned. X-unknown. 
risk of dying (RR) increased from 1.28 to 4.31 for $\mathrm{pN} 2$ (4-9 $\mathrm{N}+)$ and from 1.31 to 5.03 for $\mathrm{pN} 3(\geq 10 \mathrm{~N}+)$ and $\mathrm{P}$ values decreased from 0.5 to 0.073 for $\mathrm{pN} 2$ and 0.53 to 0.073 for $\mathrm{pN} 3$ with the number of nodes removed increasing from $>5$ to $>15$ (Table 3 ).

It is likely that some patients from the intermediaterisk LNR were understaged as $\mathrm{pN} 1$ stage as a result of the small number of nodes removed (Table 2). Further, this conclusion is supported by the number of positive nodes in the intermediate-risk LNR (median $=3$, range, $2-3)$ for groups where $\leq 10$ or $\leq 15$ nodes removed. When $\leq 15$ nodes are removed, there is a greater probability that some patients with $\geq 4$ positive nodes will be misclassified as having one to three positive nodes. This is in contrast to those patients where $>15$ nodes are removed where all $\mathrm{pN} 1$ patients were from the low-risk LNR.

Most studies of LNR in breast cancer are singleinstitution studies that create their own LNR groupings based on their institution's data (Katz et al. 2008; Voordeckers et al. 2004; van der Wal et al. 2002). The number of lymph nodes removed and examined is highly dependent on surgical technique and expertise, the institution's protocol for identifying lymph nodes and the pathologists' experience (Schaapveld et al. 2004). Our study is one of the few population based studies that examined the LNR risk categories established by previous studies (Vinh-Hung et al. 2009; Vinh-Hung et al. 2010; van der Wal et al. 2002; Danko et al. 2010; Chagpar et al. 2011) and involved a large number of surgeons with varying expertise in performing axillary clearance. The duration of follow-up in our study is longer than that in many other studies (median $=10.3$ years), which increases the ability to assess the prognostic value of the variables being investigated. Other advantages of our study are the larger median number of nodes removed $(n=15)$ and accurate follow up data with breast cancer specific survival based on information received from a centralised cancer registry which included information on cause of death.

Some authors argue that the additional information from performance of completion ALND after positive SLN biopsy may benefit patients by guiding decisions about adjuvant chemotherapy. For the approximately one-half of patients in whom there is residual nodal disease, it is also argued that complete ALND can influence survival via local-regional control of the axilla, thereby eliminating a potential site of recurrent disease and, ultimately, a source for distant disease (Straver et al. 2010; Kothari et al. 2012; Sosa et al. 1998). The standard of care for breast cancer patients with sentinel lymph node (SLN) metastases includes complete ALND (Van Zee et al. 2003). The Z-0011 trial has advocated that ALND is not necessary if $<3$ nodes are involved (Giuliano et al.
2010). Giuliano et al. (2011) summarized total nodal involvement in ALND and SLND alone groups, 21.0\% of patients undergoing ALND had 3 or more involved nodes compared with 3.7\% undergoing SLND alone (Giuliano et al. 2011). Completion ALND quantifies total nodal burden, defines prognosis and can determine adjuvant treatments in addition to maximising local disease control (Kothari et al. 2012). However, the Z-0011 data has questioned the need for completion ALND for early node-positive breast cancer treated with conservation, RT and optimal systemic therapy. Thus our data, need to be placed into context of changes in recent strategy particularly for older patients with smaller primary tumors and low sentinel node positivity particularly for luminal A tumors where RT to the axilla is also given (Jagsi et al. 2014). However, for patients with macroscopic nodal metastases in several nodes following an axillary dissection who have more than 15 nodes dissected, the oncologist can be satisfied that prognosis, selection of adjuvant chemotherapy and radiotherapy fields can be based on the numerator of the positive nodes. When patients have low node denominators and higher numerators, our data suggests that LNR is important and treatment selection may need to be intensified to take into account potential understaging of the axilla.

\section{Ethical standards}

Research conducted for the purpose of this manuscript complies with the current laws of Australia.

\section{Competing interests}

NP has received Roche Pty Ltd speaker honoraria and related travel support. The other authors declare that they have no competing interests.

\section{Authors' contributions}

UJ and JB designed the study. UJ conducted the data analysis. UJ was responsible for the first draft of the paper and JB, NP and EE for further contribution and review. All authors read and approved the final manuscript.

\section{Acknowledgements}

Financial Support: The Westmead Breast Cancer Institute receives funding from the NSW Health Department and the support of the community.

\section{Author details}

${ }^{1}$ Westmead Breast Cancer Institute, Westmead, New South Wales, Australia. ${ }^{2}$ Faculty of Medicine, University of New South Wales, Sydney, New South Wales, Australia. ${ }^{3}$ Macquarie University Cancer Institute, Macquarie University, North Ryde, New South Wales, Australia.

Received: 27 January 2015 Accepted: 29 January 2015

Published online: 11 March 2015

\section{References}

Ahn SH, Kim HJ, Lee JW, Gong GY, Noh DY, Yang JH, Jung SS, Park HY (2011) Lymph node ratio and $\mathrm{pN}$ staging in patients with node-positive breast cancer: A report from the Korean breast cancer society. Breast Cancer Res Treat 130:507-515

Berger AC, Watson JC, Ross EA, Hoffman JP (2004) The metastatic/examined lymph node ratio is an important prognostic factor after pancreaticoduodenectomy for pancreatic adenocarcinoma. Am Surgeon 70:235-240 
Berger AC, Sigurdson ER, LeVoyer T, Hanlon A, Mayer RJ, Macdonald JS, Catalano PJ, Haller DG (2005) Colon cancer survival is associated with decreasing ratio of metastatic to examined lymph nodes. J Clin Oncol 23:8706-8712

Boyages J, Langlands A (1998) Postmastectomy radiation therapy: better late than never. Aust N Z J Surg 68:550-553

Boyages J, Jayasinghe UW, Coombs N (2010) Multifocal breast cancer and survival: each focus does matter particularly for larger tumors. Eur J Cancer 46:1990-1996

Caudle AS, Hunt KK, Kuerer HM, Meric-Bernstam F, Lucci A, Bedrosian I, Babiera GV, Hwang RF, Ross MI, Feig BW, Hoffman K, Litton JK, Sahin AA, Yang W, Hortobagyi GN, Buchholz TA, Mittendorf EA (2011) Multidisciplinary considerations in the implementation of the findings from the American college of surgeons oncology group (ACOSOG) Z0011 study: A practice-changing trial. Ann Surg Oncol 18:2407-2412

Chagpar AB, Scoggins CR, Martin li RCG, Carlson DJ, Laidley AL, El-Eid SE, MCGlothin TQ, McMasters KM (2006) Prediction of sentinel lymph node-only disease in women with invasive breast cancert+A complete list of investigators in the University of Louisville Breast Sentinel Lymph Node Study is provided in Am J Surg 2002;184:496-498. Am J Surg 192:882-887

Chagpar AB, Scoggins CR, Martin li RCG, Cook EF, McCurry T, Mizuguchi N, Paris KJ, Carlson DJ, Laidley AL, El-Eid SE, McGlothin TQ, McMasters KM (2007) Predicting patients at low probability of requiring postmastectomy radiation therapy. Ann Surg Oncol 14:670-677

Chagpar AB, Camp RL, Rimm DL (2011) Lymph node ratio should be considered for incorporation into staging for breast cancer. Ann Surg Oncol 18:3143-3148

Chua B, Ung O, Taylor R, Boyages J (2002) Is there a role for axillary dissection for patients with operable breast cancer in this era of conservatism? Aust N Z J Surg 72:786-792

Danko ME, Bennett KM, Zhai J, Marks JR, Olson JA Jr (2010) Improved staging in node-positive breast cancer patients using lymph node ratio: results in 1,788 patients with long-term follow-up. J Am Coll Surg 210:797-805

Dings PJM, Elferink MAG, Strobbe LJA, de Wilt JHW (2013) The prognostic value of lymph node ratio in node-positive breast cancer: a Dutch nationwide population-based study. Ann Surg Oncol 20:2607-2614

Duraker N, Batı B, Caynak ZC, Demir D (2013) Lymph node ratio may be supplementary to TNM nodal classification in node-positive breast carcinoma based on the results of 2,151 patients. World J Surg 37:1241-1248

Fisher B, Wolmark N, Bauer M, Redmond C, Gebhardt M (1981) The accuracy of clinical nodal staging and of limited axillary dissection as a determinant of histologic nodal status in carcinoma of the breast. Surg Gynecol Obstet 152:765-772

Fisher B, Redmond C, Fisher ER, Bauer M, Wolmark N, Wickerham DL, Deutsch M, Montague E, Margolese R, Foster R (1985) Ten-year results of a randomized clinical trial comparing radical mastectomy and total mastectomy with or without radiation. N Engl J Med 312:674-681

Giuliano AE, McCall L, Beitsch P, Whitworth PW, Blumencranz P, Leitch AM, Saha S, Hunt KK, Morrow M, Ballman K (2010) Locoregional recurrence after sentinel lymph node dissection with or without axillary dissection in patients with sentinel lymph node metastases: the American college of surgeons oncology group z0011 randomized trial. Ann Surg 252:426-432

Giuliano AE, Hunt KK, Ballman KV, Beitsch PD, Whitworth PW, Blumencranz PW, Leitch AM, Saha S, McCall LM, Morrow M (2011) Axillary dissection vs no axillary dissection in women with invasive breast cancer and sentinel node metastasis: a randomized clinical trial. JAMA 305:569-575

Greenberg R, Itah R, Ghinea R, Sacham-Shmueli E, Inbar R, Avital S (2011) Metastatic lymph node ratio (LNR) as a prognostic variable in colorectal cancer patients undergoing laparoscopic resection. Tech Coloproctol 15:273-279

Herr HW (2003) Superiority of ratio based lymph node staging for bladder cancer. J Urol 169:943-945

Hong KD, Lee SI, Moon HY (2011) Lymph node ratio as determined by the 7th edition of the American Joint Committee on cancer staging system predicts survival in stage III colon cancer. J Surg Oncol 103:406-410

Jagsi R, Chadha M, Moni J, Ballman K, Laurie F, Buchholz TA, Giuliano A, Haffty BG (2014) Radiation field design in the ACOSOG Z0011 (Alliance) trial. J Clin Oncol 32:3600-3606

Jonnalagadda S, Arcinega J, Smith C, Wisnivesky JP (2011) Validation of the lymph node ratio as a prognostic factor in patients with $\mathrm{N} 1$ nonsmall cell lung cancer. Cancer 117:4724-4731

Katz A, Smith BL, Golshan M, Niemierko A, Kobayashi W, Raad RA, Kelada A, Rizk L, Wong JS, Bellon JR, Gadd M, Specht M, Taghian AG (2008) Nomogram for the prediction of having four or more involved nodes for sentinel lymph node-positive breast cancer. J Clin Oncol 26:2093-2098

Kothari MS, Rusby JE, Agusti AA, MacNeill FA (2012) Sentinel lymph node biopsy after previous axillary surgery: a review. Eur J Surg Oncol 38:8-15

Krag DN, Single RM (2003) Breast cancer survival according to number of nodes removed. Ann Surg Oncol 10:1152-1159

Krag D, Weaver D, Ashikaga T, Moffat F, Klimberg VS, Shriver C, Feldman S, Kusminsky R, Gadd M, Kuhn J, Harlow S, Beitsch P, Whitworth P, Foster R, Dowlatshahi K (1998) The Sentinel node in breast cancer. A multicenter validation study. N Engl J Med 339:941-946

Li Y, Holmes E, Shah K, Albuquerque K, Szpaderska A, Ersahin C (2012) The prognostic value of lymph node cross-sectional cancer area in node-positive breast cancer:A comparison with N stage and lymph node ratio. Pathol Res Int. doi:10.1155/2012/161964

Matsuguma H, Oki I, Nakahara R, Ohata N, Igarashi S, Mori K, Endo S, Yokoi K (2012) Proposal of new nodal classifications for non-small-cell lung cancer based on the number and ratio of metastatic lymph nodes. Eur J Cardiothorac Surg 41:19-24

McMasters KM (2003) The eternally enigmatic axilla: further controversy about axillary lymph nodes in breast cancer. Ann Surg Oncol 10:1128-1130

National Comprehensive Cancer Network (2013) Clinical Practice Guidelines in Oncology (NCCN Guidelines)., http://www.nccn.org/professionals/default. aspx. Accessed 15 December 2014

Overgaard M, Hansen PS, Overgaard J, Rose C, Andersson M, Bach F, Kjaer M, Gadeberg CC, Mouridsen HT, Jensen MB, Zedeler K (1997) Postoperative radiotherapy in high-risk premenopausal women with breast cancer who receive adjuvant chemotherapy. N Engl J Med 337:949-955

Rabban J (2010) The New Edition (7th) AJCC Staging System for Breast Cancer: A Summary of Key Changes. Pathology Department, University of California, San Francisco, http://labmed.ucsf.edu/uploads/210/ 101_new_ajcc_staging_of_breast_cancer_what_has_changed.pdf Accessed 15 December 2014

Ragaz J, Jackson SM, Le N, Plenderleith IH, Spinelli JJ, Basco VE, Wilson KS, Knowling MA, Coppin CML, Paradis M, Coldman AJ, Olivotto IA (1997) Adjuvant radiotherapy and chemotherapy in node-positive premenopausal women with breast cancer. N Engl J Med 337:956-962

Saxena N, Hartman M, Yip CH, Bhoo-Pathy N, Khin LW, Taib NA, Looi LM, Lim SE, Lee SC, Verkooijen HM (2012) Does the axillary lymph node ratio have any added prognostic value over pN staging for South East Asian Breast Cancer Patients? PLoS ONE 7(9):e45809, doi:10.1371/journal.pone.0045809

Schaapveld M, Otter R, De Vries EGE, Fidler V, Grond JAK, Van Der Graaf WTA, De Vogel PL, Willemse PHB (2004) Variability in axillary lymph node dissection for breast cancer. J Surg Oncol 87:4-12

Schiffman SC, McMasters KM, Scoggins CR, Martin RC, Chagpar AB (2011) Lymph node ratio: a proposed refinement of current axillary staging in breast cancer patients. J Am Coll Surg 213:45-52

Singletary SE, Allred C, Ashley P, Bassett LW, Berry D, Bland Kl, Borgen PI, Clark GM, Edge SB, Hayes DF, Hughes LL, Hutter RVP, Morrow M, Page DL, Recht A, Theriault RL, Thor A, Weaver DL, Wieand HS, Greene FL (2003) Staging system for breast cancer: revisions for the 6th edition of the AJCC Cancer Staging Manual. Surg Clin North Am 83:803-819

Sosa JA, Diener-West M, Gusev Y, Choti MA, Lange JR, Dooley WC, Zeiger MA (1998) Association between extent of axillary lymph node dissection and survival in patients with stage I breast cancer. Ann Surg Oncol 5:140-149

Straver ME, Meijnen P, Van Tienhoven G, Van De Velde CJH, Mansel RE, Bogaerts J, Demonty G, Duez N, Cataliotti L, Klinkenbijl J, Westenberg HA, Van Der Mijle H, Hurkmans C, Rutgers EJT (2010) Role of axillary clearance after a tumor-positive sentinel node in the administration of adjuvant therapy in early breast cancer. J Clin Oncol 28:731-737

Tong LL, Gao P, Wang ZN, Song YX, Xu YY, Sun Z, Xing CZ, Wang X, Xu HM (2011) Can lymph node ratio take the place of pN categories in the UICC/AJCC TNM classification system for colorectal cancer? Ann Surg Oncol 18:2453-2460

Truong PT, Berthelet E, Lee J, Kader HA, Olivotto IA (2005) The prognostic significance of the percentage of positive/dissected axillary lymph nodes in breast cancer recurrence and survival in patients with one to three positive axillary lymph nodes. Cancer 103:2006-2014

Truong PT, Vinh-Hung V, Cserni G, Woodward WA, Tai P, Vlastos G (2008) The number of positive nodes and the ratio of positive to excised nodes are significant predictors of survival in women with micrometastatic node-positive breast cancer. Eur J Cancer 44:1670-1677 
Truong PT, Lesperance M, Li KH, MacFarlane R, Speers CH, Chia S (2010) Micrometastatic node-positive breast cancer: Long-term outcomes and identification of high-risk subsets in a large population-based series. Ann Surg Oncol 17:2138-2146

van der Wal BCH, Butzelaar RMJM, van der Meij S, Boermeester MA (2002) Axillary lymph node ratio and total number of removed lymph nodes: predictors of survival in stage I and II breast cancer. Eur J Surg Oncol 28:481-489

Van Zee KJ, Manasseh DME, Bevilacqua JLB, Boolbol SK, Fey JV, Tan LK, Borgen PI, Cody lii HS, Kattan MW (2003) A nomogram for predicting the likelihood of additional nodal metastases in breast cancer patients with a positive sentinel node biopsy. Ann Surg Oncol 10:1140-1151

Vinh-Hung V, Burzykowski T, Cserni G, Voordeckers M, Van De Steene J, Storme G (2003) Functional form of the effect of the numbers of axillary nodes on survival in early breast cancer. Int J Oncol 22:697-704

Vinh-Hung V, Verkooijen HM, Fioretta G, Neyroud-Caspar I, Rapiti E, Vlastos G, Deglise C, Usel M, Lutz JM, Bouchardy C (2009) Lymph node ratio as an alternative to $\mathrm{pN}$ staging in node-positive breast cancer. J Clin Oncol 27:1062-1068

Vinh-Hung V, Joseph SA, Coutty N, Ly BH, Vlastos G, Nguyen NP (2010) Age and axillary lymph node ratio in postmenopausal women with T1-T2 node positive breast cancer. Oncologist 15:1050-1062

Voordeckers M, Vinh-Hung V, Van De Steene J, Lamote J, Storme G (2004) The lymph node ratio as prognostic factor in node-positive breast cancer. Radiother Oncol 70:225-230

Vrana D, Gatek J, Cwiertka K, Lukesova L, Koranda P (2013) Internal mammary node management in breast cancer. A review. Biomed Papers 157(3):261-265

Wang F, He W, Qiu H, Wang X, Guo G, Chen X, Rong Y, Zhou F, Yin C, Yuan Z, $X i a ~ L(2012)$ Lymph node ratio and $p N$ staging show different superiority as prognostic predictors depending on the number of lymph nodes dissected in chinese patients with luminal a breast cancer. Clin Breast Cancer 12:404-411

Woodward WA, Vinh-Hung V, Ueno NT, Yee CC, Royce M, Tai P, Vlastos G, Wallace AM, Hortobagyi GN, Nieto Y (2006) Prognostic value of nodal ratios in node-positive breast cancer. J Clin Oncol 24:2910-2916

Yiangou C, Shousha S, Sinnett HD (1999) Primary tumour characteristics and axillary lymph node status in breast cancer. Br J Cancer 80:1974-1978

Zhou J, Griffith KA, Hawley ST, Zikmund-Fisher BJ, Janz NK, Sabel MS, Katz SJ, Jagsi R (2013) Surgeons' knowledge and practices regarding the role of radiation therapy in breast cancer management. Int J Radiation Oncol Biol Phys 87:1022-1029

\section{Submit your manuscript to a SpringerOpen ${ }^{\circ}$ journal and benefit from:}

- Convenient online submission

- Rigorous peer review

- Immediate publication on acceptance

- Open access: articles freely available online

- High visibility within the field

- Retaining the copyright to your article

Submit your next manuscript at $>$ springeropen.com 